\title{
Peertechz
}

\section{Assessment of immigrant detention centers and detainees health status in}

\section{Libya}

\author{
Adel El Taguri ${ }^{1,2 *}$ and Aisha Nasef ${ }^{3,4}$ \\ ${ }^{1}$ National Center for Accreditation of Health Establishments, Libya \\ ${ }^{2}$ Community Department, University of Tripoli, Libya \\ ${ }^{3}$ Authority of Natural science Research and Technology, Libya \\ ${ }^{4}$ Scientific Council of Laboratory Medicine, Medical Specialty council, Libya
}

Received: 12 April, 2021

Accepted: 04 May, 2021

Published: 05 May, 2021

*Corresponding author: Adel El Taguri, National Center for Accreditation of Health Establishments, Libya, Tel: + 218910419561; E-mail: Tajoury@cahel.org.ly

Keywords: Immigrant; Detention centers; Detainees; Health status; Libya

https://www. peertechzpublications.com

Check for updates

\begin{abstract}
Migrants are extremely vulnerable to various risks including the lack of physical and mental health care. The weakness of the health system in Libya is further undermined by the fragile, insecure, limited access, threats to health care workers and the increased social and economic challenges. This study studied the general environment of Detention Centers (DCs) of migrants in Libya and their health. Information were collected by during visits to DCs using to assess the structure, organization, financing, processes occurring in the center upon arrival of detainees, accommodation, water, sanitation and hygiene, food and nutrition, health-care services, and health status of detainees including their general health, chronic conditions, acute challenges as infections including TB, STD/HIV, hepatitis and malaria, and violence. Mental health was assessed using standard tools. Special questions were constructed for pregnant females and under five children. Sixteen DCs were visited. Thirteen of them had children in their premises, while ten detained women. Of the 427 interviewed, more than half were younger than 25 years of age. Overall environment and amenities were inadequate or poor. In more than half of DCs, deliveries did occur inside the DC itself. According to DCs managers, most common causes of death were TB, malnutrition and depression. The prevalence of acute and chronic illnesses including mental conditions were determined. Specific actions are proposed to each in particularly establishing/reviving a dedicated health center to meet the individual and public health needs of migrants.
\end{abstract}

\section{Introduction}

The world is currently facing what seems to be the largest ever wave of Displaced-Immigrant-Refugee "DIR" population in history. The Eastern Mediterranean Region (EMR) is carrying the largest burden as more than half of these are in this region. Libya has always been an attractive departure point for economic migrants from Africa and the Middle East. With the longest coast on the Mediterranean in its northern border and the long and difficult to protect other borders, Libya became a major cross-road to Southern Europe not only for human traffic and irregular immigration. At the end of the previous decade, it was estimated that there were more than one and half million immigrants in Libya. The environment for humanitarian actors in countries of the the whole region is fragile, insecure with limited access; threats to health care workers; and increased social and economic challenges. Libya is a particular case in the region as most of these migrants are of mixed origin populations that are coming from even remote areas and for many variable reasons.

As DIR are extremely vulnerable to human rights abuses, particularly the lack of/or denial of physical and mental health care, protection services should be made available and strengthened to vulnerable migrants with particular emphasis on victims of trafficking (VoTs); Unaccompanied Migrant Children (UMC); migrants with serious medical conditions (including HIV/AIDS); and other categories of those at-risk.

Despite the current situation consisting of insecurity, a lack of rule of law and the loss of financial stability, Libya is still an important transit and destination country for migrants. In certain instances, migrants remain stranded in Libya and are 
caught by the authorities, or they become easy targets for the smuggling networks which promise safe travel to desperate people willing to embark on a dangerous trip by sea to Europe.

Since 2014 transiting migrants, primarily from East and West Africa have continued to exploit Libyan political instability and weak border controls and use the country as a primary departure point to migrate across the central Mediterranean to Europe [1]. The total population of migrants in Libya had been about 700,000 - 1 million people, mainly coming from Egypt, Niger, Sudan, Nigeria, Bangladesh, Syria, and Mali. The constant tragedies in the Mediterranean, coupled with the deteriorating situation of the local population, make it necessary to address the instability in Libya through various interventions. The Department for Combating Illegal Migration (DCIM), affiliated to the Interior Ministry, managed the formal migrant detention centers. Of note, there are non-formal migrant detention centers ran by smugglers and traffickers.

Libya's health sector capacity has been burdened and under-resourced. The repeated emergencies have not allowed a proper recovery of public sector services. A Service Availability and Readiness Assessment survey, conducted by the WHO and the ministry of health, showed that health system has practically collapsed [2]. Although Libya's health system is largely a public-health oriented health system, it is weak in essence, with debilitated Primary Health-Care (PHC) network, and neglected health services. There were only few previous activities for assessment of migration and of Detention Centers (DCs) conditions that were performed [3]. These assessments concluded that more services should be tailored to these vulnerable Migrants.

In this study, a survey was designed to assess objectively the general environment in and surrounding the DCs in Libya and the corresponding health situation of the detained immigrants.

\section{Materials and methods}

\section{Population and data collection}

Information was collected by different qualitative and quantitative means. It include structured visits to DCs all over Libya using standard questionnaires and discussion with detainees. The focus of the current survey is the status of immigrants in DCs. The list includes all DCIM affiliated and not affiliated DCs to construct a better picture of the situation and challenges facing Immigrants in Libya.

It should be noted that these would only represent a fraction of the total number of immigrants in the country as thousands of immigrants are employed and are contributing actively in Libyan society. The assessment done involved all stakeholders and included accommodation, water, sanitation and hygiene, food and nutrition, health-care services, and health status of detainees.

\section{Assessment tools}

The survey involved two questionnaires. First questionnaire was designed to gather data about DCs. The second questionnaire was designed to collect data from detainees.

\section{Detention centers tool}

First questionnaire contains general data about visited centers including structure, organization, financing, processes occurring in the center upon arrival of detainees and how is health taken care of in addition to shelter and hygiene (Appendix 1).

\section{Detainees tool}

Second questionnaire contains questions addressed to detainees in order to assess their general health, chronic conditions, acute diseases in particular infections and violence that they might have been exposed to. Other data obtained regarding general health and some of the most important infections as tuberculosis, STD/HIV, hepatitis and malaria. mental health using standard mental health tools. Special appendices were constructed for pregnant females and under five children and added to this tool.

\section{Results}

\section{Detention centers}

Sixteen DCs were visited. Fifteen of these DCs are recognized as affiliated to the designed authority by the Libyan government (DCIM), and one non- affiliated and permitted visiting and surveying of detainees. Ten $(62.50 \%)$ DCs find that the budget was not enough the last year. Thirteen DCs $(81.25 \%)$ have children in their premises. Three $(18.75 \%)$ of these contain more than 50 children. Ten $(62.50 \%)$ of these centers also detain women. One center contains 520 women.

Among DCs, only three centers were considered part of National program for Immunization, two centers for TB and only one center for HIV. In 12 of these DCs, the health Unit works only during official working hours (Till $14 \mathrm{hr}$ ). Water supply was considered adequate in 13 DCs (81.3\%). Five (31.25\%) of DCs have visible fissures in the walls and/or ceilings. Humidity (molds) was visible to naked eye in one of DCs. There is evidence of dense presence of insect and/or rodents in seven (46.7\%) DCs. In only two DCs, bed linen and covertures were appropriate. They were regularly cleaned and replaced in seven $(43.8 \%)$ DCs. Enough beds were reported in five (less than $1 / 3$ ) of the visited DCs.

Detainees are allowed in open air in all DCs. In six (43.8\%) DCs, they are allowed just one hour or less. The remaining DCs allow detainees to stay in open air for more than two hours per day. Detainees in almost $2 / 3$ of DCs work during their detention. In most of the cases this happens inside the DCs.

In only five DCs, food presented was of enough quantity. One third of DCs receive food donations, but this occurs less than twice per month. Premises where food is prepared was not considered suitable in more than $3 / 4$ of DCs. Forty three percent of food handlers are not trained. Soap was not available in $42.9 \%$ of food distribution halls. In two DCs, hygiene in food halls was poor or very poor.

Only in three DCs, the medical unit supervises hygiene in DC premises. In quarter of DCs, there are no regular visits by 
medical staff. Two-fifth of DCs refers sick detainees to privet clinics and $1 / 3$ to public hospitals.

It is necessary to have a pre-requested permission to seek medical advice in seven $(43.8 \%)$ of DCs. Two-Thirds find that this permission to seek medical advice was fast and more than $90 \%$ found it easy enough to obtain the permission.

There was an isolation room in $71.4 \%$ of DCs. According to staff, $84.6 \%$ consider that they need more drugs. In only nine DCs, newcomers are subjected to medical assessment at entry. In more than half of DCs, deliveries did occur inside the DC itself. More than 3/4 of DCs have reported cases of scabies and/or pediculosis. In two DCs, detainees were reported to have scorpion/snake bites. More than 2/5 detainees reported exposure to some form of violence, half of them outside the DC before his arrival. In only two DCs there were health promotion activities which were devoted to mental health.

More than $90 \%$ do not keep files for patients, but half keep registers for them. In about $2 / 3$ of DCs the access to these documents are not limited to physicians. Informed consent is only requested in three DCs before blood investigations were performed. Most common causes of death among detainees are Tuberculosis, malnutrition and depression according to DCs managers.

\section{Detainees}

Number of detainees interviewed was 427. The highest number was in Gharian DC, where 90 detainees were met. Tajoura follows (71 detainees) and Zwara (61 detainees). Most of detainees were from Sudan (Darfur in particular) followed by Eretria and Somalia (86, 54, and 52 respectively).

The age range of detainees in DCs is $13-63$ years. More than half of them are younger than 25 years of age. More than half of detainees $(62.2 \%)$ spent more than a year in the DCs. Although $224(52.46 \%)$ of them either did not have a job before arrival or did not specify it, the job range of detainees varied widely. Some of detainees were farmers, construction workers, nurses, engineers, English teachers, clothes designers, and carpenters.

Two-fifth of detainees had acute diarrhea in the six months preceding the survey and about $7 \%$ had food poisoning. While one third had skin diseases as scabies and/or pediculosis, $14.7 \%$ had respiratory infections and 3\% reported snake/scorpion bites during the same period (Figure 1). Seventy three detainees $(17.10 \%)$ reported having a chronic disease. The types of illness and the number of detainees affected are shown in DCs (Figure 2).

One hundred fifty $(35.10 \%)$ detainees reported that they were exposed to some form of physical violence from the start of the journey till arrival to DC. The majority of these incidents of abuse (125) had been exposed to violence during the journey either outside Libya (30 detainees, $7.0 \%$ ) or inside Libya (90 detainees, $21.1 \%$ ) or in both (five detainees, $3.6 \%$ ). The remaining 25 detainees had been exposed to violence during arrest or inside current or previous DC. The type of physical violence they were exposed to is shown in (Figure 3).

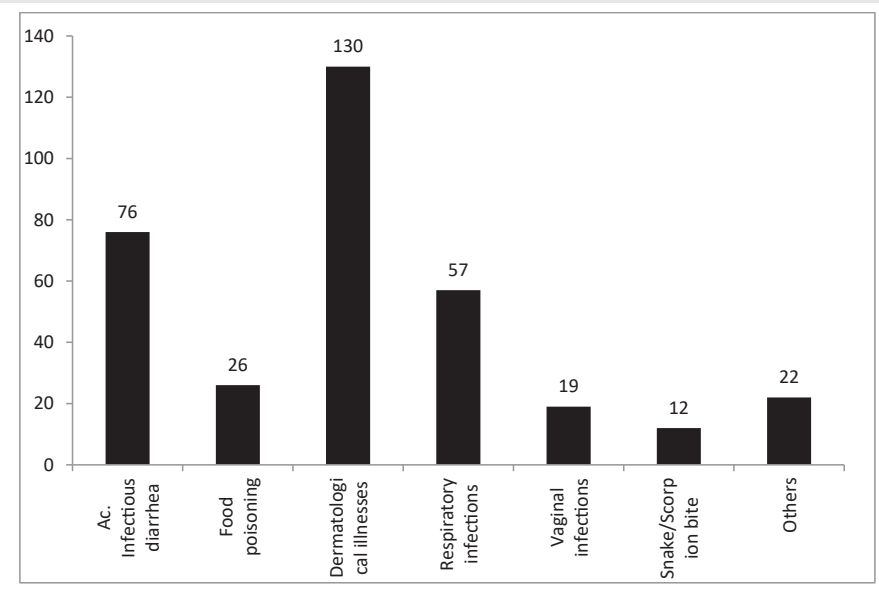

Figure 1: Self-reported acute illness among 427 detainees in preceding six months.

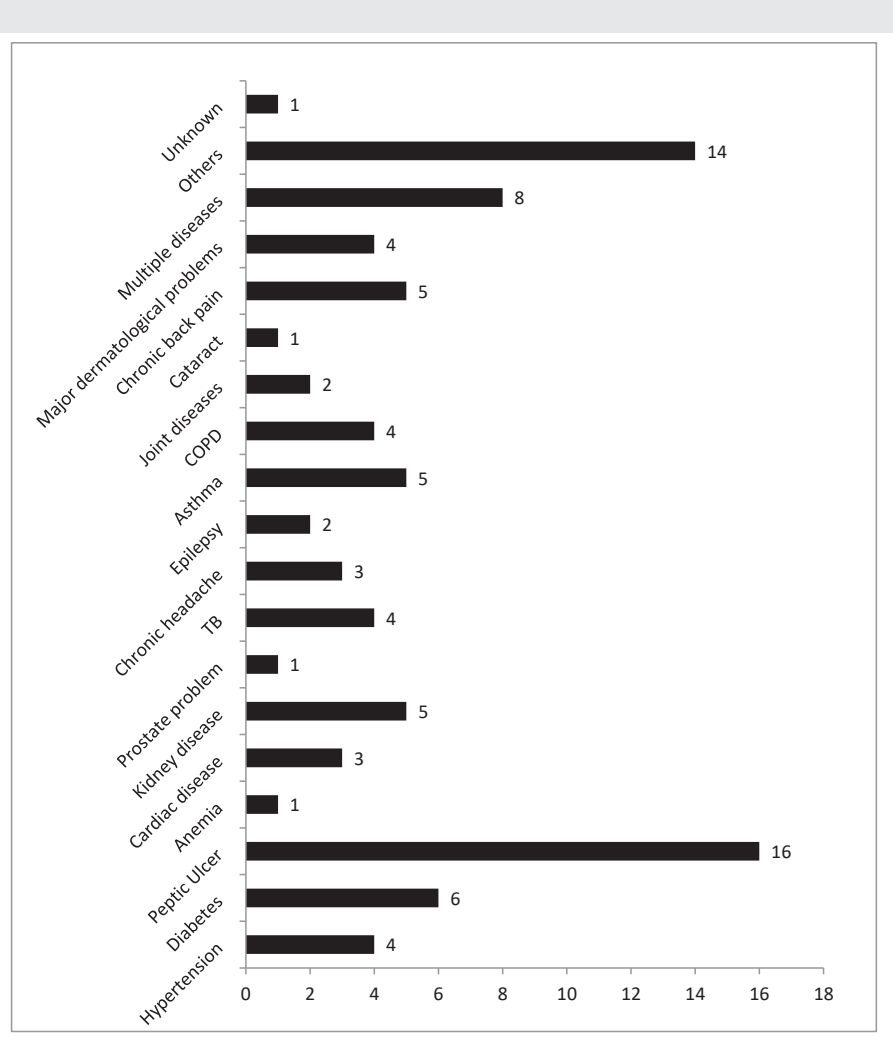

Figure 2: Distribution of detainees according to self-reported chronic illness.

One-third (52 detainees) had depression according to PHQ2 screening tool while half had anxiety (Table 1) and only $7 \%$ had Post traumatic Stress Disorders (PTSD). More than half of detainees were not satisfied with the medical services delivered to them.

There were 32 pregnant women. About half of them $(46.9 \%)$ did not have antenatal visits. The non-presence of complications and the non-availability of the service were the most common reasons (almost $1 / 3$ for each of them).

Fifty one children under five years of age were approached. Almost $1 / 3$ had diarrhea and 2/5 had cough and respiratory difficulty in the two weeks preceding the survey. Symptoms of stress among children as difficulty sleeping (41.2\%) and frequent and easily crying (29.4\%) were also frequent. 


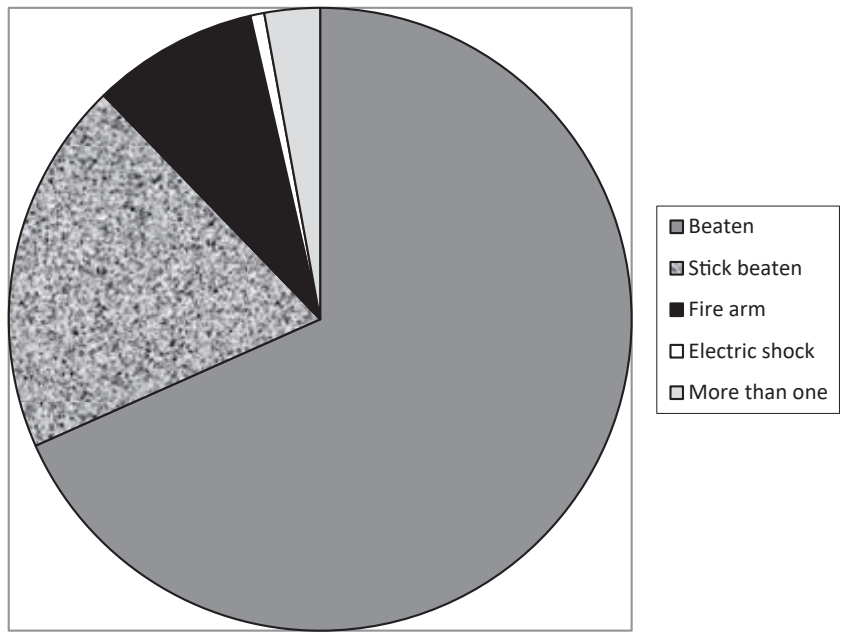

Figure 3: The type of physical violence the detainees were exposed to during the journey until arrival to current $D C$.

Table 1: Prevalence of depression and anxiety among 427 detainees.

Prevalence of depression and anxiety among 427 detainees

Prevalence of depression

Prevalence of Anxiety
No

Mild

Moderate

Moderate-Sever

Sever
$28 \%$

$36 \%$

$22 \%$

$9 \%$

$5 \%$

\section{Discussion}

This survey tried to look to the issue of migration from different complementary perspectives including the inner environment in the DCs. Thought, the focus of the survey is the status of immigrants in DCs, it should be noted that "detainees" would only represent a small fraction of the total number of real immigrants.

Infections are usually considered as major environmental hazard in mass gathering. All shelter residents should use "General Infection Prevention Measures" to reduce the spread of infections and infectious diseases [4]. Standard precautions should be applied to all residents in DCs to protect residents and staff alike. Personal protective equipment (e.g., gloves, masks, and gowns) should be provided for healthcare personnel who staff the special-needs shelter. Each resident should be screened at the time of entry to the special needs shelter to detect any conditions necessitating isolation and/or use of Transmission-Based Precautions [5].

Of paramount importance is the appropriate practice of Hand Hygiene. In addition, proper techniques to use when washing your hands with soap and water and techniques for hand washing with alcohol-based products should be followed.

Protein-Energy-Malnutrition (PEM) remains the most common nutritional problems. In recent years more and more micronutrient deficiency diseases are recognized among migrant populations entirely dependent on external food aid.

While humanitarian aid usually focuses on the immediate physical needs of migrants like clean water, food, and shelter, it often overlooks mental health. Violence and displacement increases the need for mental health services, especially for women and children. Both questionnaires for detainees and workers in the current survey used standard validated mental health tools (PHO9, GAD7 and PC-PTSD). The full version of the PHQ-9 and GAD-7 that were used screened for the presence of depression and anxiety, but also to assess their severity. Major issues and general measures to tackle them are presented in the following tables (Tables 2,3). Psychiatric disorders, like Post Traumatic Stress Disorder, mental exhaustion and chronic fatigue syndrome effect many migrants [6]. These disorders greatly affect the long-term quality of life for migrants.

Non-Communicable Diseases (NCD) also constitute a major health threat for displaced populations and for migrants who have found themselves at increasing risk of deteriorating health status. A significant number of migrants suffer from chronic diseases such as hypertension, cardiovascular diseases, diabetes and cancer, all requiring costly and long-term treatment. The most frequently observed NCDs are asthma/ chronic obstructive pulmonary disease (COPD), diabetes, hypertension and cardiovascular diseases.

It has to be clearly stated that migrants are coming from different physical and social environmental backgrounds. They had left their places of origin due to many reasons. In much of the cases, this is due to unfavorable socioeconomic conditions. These unfavorable conditions would particularly further increase health risks before, during, and after migration. This is particularly so for infections, nutrition and mental health issues. For chronic illnesses, the loss of the continuity of management would further contribute to health hazards if not properly taken care off.

Specific actions to be proposed, process owner(s) and other stakeholders to be discussed according to the nature of these measures, to input from the various stakeholders and depending upon local circumstances. It's of paramount importance strategically to establish a dedicated health center to meet the individual and public health needs, as most of these proposed measures would be effectively and efficiently realized by such center. In addition to the unfamiliarity and low level of knowledge among care provider regarding the pathologies the migrants are particularly exposed to, the vulnerability of migrants to many of the illness they are exposed to before, during and after migration would require a particular set of skills. The presumed center would implement the executive functions handled to them by the currently established division at the Ministry of Health and implemented by many fragmented service providers. It could also function as a house of experience for these morbidity and mortality pattern in the country and in the whole region. 
Table 2: Main issues and proposed measures related to migration and impact of health on individuals and public in Libya (Detention Centers).

$$
\text { Main Issues }
$$

Budget not enough for running DCs and meet requirements

Many DCs detain children and women

Visible fissures in the walls and/or ceilings, humidity (molds)

Evidence of dense presence of insect and/or rodents. Inadequate water supply in some DCs

Health unit works only during official working hours

Many DCs were not considered part of National programs for Immunization, TB, or HIV.

Non regular cleaning and replacement of bed linen

Inadequate number of beds

Inadequate quantities of food. Limited external Aid that is almost non-existent.

Non-suitable food promises, poor hygiene, limited availability of soaps.

Non-trained food handlers

Medical Units not supervising hygiene in food premises. hygiene in food halls was poor or very poor

Referral of sick detainees to privet clinics and public hospitals.

The necessity of having a pre-requested permission to seek medical advice. Some DCs find that the permission to seek medical advice albeit easy, but for some might not be as fast. $>90 \%$ do not keep files for patients, but $1 / 2$ keep registers for them. $\approx 2 / 3$ of DCs, the access to these documents are not limited to physicians.

Informed consent is not universally requested before performing blood investigation.

Not all DCs have isolation rooms.

Shortages of drug supplies as perceived by DC managers.

Not all newcomers are subjected to medical assessment at entry.

Limited health promotion activities which were devoted to mental health.

$>3 / 4$ of DCs have reported cases of scabies and/or pediculosis.

Reported cases of scorpion/snake bites.

$>2 / 5$ were subjected to some form of violence, $1 / 2$ of them outside the DC before their arrival.

Most common causes of death among detainees according

to DCs managers are Tuberculosis, Malnutrition, and Depression.
Ensuring and allocating adequate resources from different local and international sources

Special consideration to the presence of women and children and vulnerable groups in DCs.

Constructing, maintaining, or allocating suitable buildings to be used for detention if needed or if considered as a must.

Training on/outsourcing service to institutions or agencies for insuring insect/rodent free premises.

Measures for insuring adequate water supply to all DCs. Might include relocation of detainees.

Insuring $24 \mathrm{hrs}$ coverage of basic medical/health services in each facility or through networking. Networking is mandatory for services not to be delivered by the health unit.

Considering migrants (intra/Extra mural) in planning and delivering services within national vertical programs as tuberculosis, HIV/STDs, immunizations and others.

Insuring appropriate amenities (regular cleaning and replacement), introducing appropriate hostel/room services.

Allocating of resources financial and goods.

Allocation of resources, provision of adequate food supply, insuring regular consistent well-supervised donations.

Constructing, maintain food halls within DCs, implementing standards of food delivery in collective settings, provision of sanitary goods as soaps and towels.

HACCP training/certification of food distributors and handlers according to norms

Standardization of health/medical package delivered in DCs to include food safety, food hygiene and food handling.

Standardization and proactive organization of referral system process including the trigger, flow, documentation and payment if necessary.

Standardization and proactive organization of referral system process including the trigger, flow, documentation and payment.

Proper registration and record keeping that contain data that would be useful for planning and management and also for proper follow-up of patients including data needed for the future and upon departure while keeping the data secured.

Raising collective, community and personnel awareness including legislative, religious, professionalism and good manners, ethics and human rights.

Restructuring and financing of medical units.

Provision of enough but supervised drug supply (drug management system)

Standardization of procedures and process in management of detainees from detention till departure including all dimension of health (physical, mental and social wellbeing) and to include promotive, preventive, curative, rehabilitative and palliative healthcare services. Special focus on fragile groups as pregnant women, children, elderly and adolescents.

Standardization of management of detainees including all dimension of health (physical, mental and social wellbeing) and to include promotive, preventive, curative, rehabilitative and palliative healthcare services. Special focus on fragile groups as pregnant women, children, elderly and adolescents.

Proper sanitation and hygiene of premises and individuals.

Location of centers to be in safe places, protective measures including those against dangerous insects/ animals.

Raising collective, community and personnel awareness including legislative, religious, professionalism and good manners, ethics and human rights.

Special emphasis in medical services on infectious diseases, mental health and proper nutrition and provision of adequate food supply. These should include early detection and active surveillance and management.

Table 3: Main issues and proposed measures related to migration and impact of health on individuals and public in Libya (Detainees).

The age range of detainees in DCs (13-63) years. $>1 / 2$ are $<25$ years of age. Presence Particular attention to various health needs of different population age groups and of Children and women

$>1 \frac{1}{2}$ of detainees $(62.2 \%)$ spent $>1$ year in the DCs.

$>1 / 2$ had no job before arrival or did not specify it, The job range of detainees varied widely: Farmers, Construction workers, Nurses, Engineers, English teachers, Clothes designers, Carpenters

In the 6 months preceding the survey, 2/5 of detainees had acute diarrhea, $7 \%$

had food poisoning, $1 / 3$ skin diseases as scabies and/or pediculosis, $14.7 \%$ had respiratory infections, $3 \%$ reported snake/scorpion bites different public health risk imposed by these groups.

Speeding of measures to normalize the life of detainees by regularization and/or deportation of migrants.

Regularization of status of migrants who could participate in development of loca economy.

Improving service delivery to detainees including general hygiene, proper nutrition and provision of safe food

Emphasis to be put on promotive, preventive and early detection measures,

Citation: Taguri AE, Nasef A (2021) Assessment of immigrant detention centers and detainees health status in Libya. J Civil Eng Environ Sci 7(1): 025-030. DOI: https://dx.doi.org/10.17352/2455-488X.000041 
$>17.10 \%$ reported having a chronic disease, Some of the most common diseases:

$1 / 3$ of detainees reported exposure to some form of physical violence. Mainly during the journey whether outside Libya (7.0\%), inside Libya (21.1\%), or in both (3.6\%). Remaining during arrest or inside a DC (current or previous).

$1 / 3$ of detainees have depression, $1 / 2$ have anxiety, $7 \%$ have PTSD.

$>1 / 2$ of detainees were not satisfied with the medical services delivered to them.

Many pregnant women. $\approx 1 / 2(46.9 \%)$ did not have antenatal visits. Mostly due to the non-presence of complications and the non-availability of the service.

$1 / 3$ of $<5$ years children had diarrhea in the 2 weeks preceding the survey and $2 / 5$ had cough and respiratory difficulty.

Symptoms of stress among children (Difficulty sleeping (41.2\%), Frequent and easily crying (29.4\%))

Immunization coverage and MUAC could not be obtained.

\section{References}

1. European Commission (2017) European Civil Protection and Humanitarian Aid Operations - Libya. European Commission.

2. Zarocostas $\mathrm{J}(2018)$ Libya: war and migration strain a broken health system Lancet 391: 824-825. Link: https://bit.ly/2SkF8Z7

3. Bisrat F, Berhane Y, Mamo A, Asefa E (1995) Morbidity Pattern Among Refugees in Eastern Ethiopia. East Afr Med J I 72: 728-730. Link: https://bit.ly/3edd7eD
Setting standards for the essential health package for migrants including guidelines for chronic diseases and insuring delivery of needed drugs.

Raising collective, community and personnel (medical and law enforcement) awareness including legislative, religious, professionalism and good manners, ethics and human rights.

Inclusion of mental health disturbances in health package for detainees.

Increasing effectiveness, establishing confidence and lifting barriers for increasing accessibility between healthcare service providers and detainees.

Increasing effectiveness, establishing confidence and lifting barriers for increasing accessibility between healthcare service providers and detainees. Special emphasis on needs of vulnerable groups (reproductive health).

Special emphasis on promotional, preventive, early detection, active surveillance and appropriate management needs of children.

Special emphasis on needs of this vulnerable groups

Special emphasis on Child health needs

4. Center for Disease Control and Prevention. General Infection Prevention Techniques. Infection Control Prevention Guidance for Community Shelters Following Disasters. Department of Health and Human Services, Atlanta, 2005

5. Center of Disease Control and Prevention. Transmission-Based Precautions.

6. Bisrat F, Berhane Y, Mamo A, Asefa E (1995) Morbidity Pattern Among Refugees in Eastern Ethiopia. East African Medical Journal 72: 728-730. Link: https://bit.ly/3nHC7Og
Discover a bigger Impact and Visibility of your article publication with Peertechz Publications

\section{Highlights}

* Signatory publisher of ORCID

* Signatory Publisher of DORA (San Francisco Declaration on Research Assessment)

* Articles archived in worlds' renowned service providers such as Portico, CNKI, AGRIS, TDNet, Base (Bielefeld University Library), CrossRef, Scilit, J-Gate etc.

* Journals indexed in ICMJE, SHERPA/ROMEO, Google Scholar etc.

* OAI-PMH (Open Archives Initiative Protocol for Metadata Harvesting)

* Dedicated Editorial Board for every journal

* Accurate and rapid peer-review process

* Increased citations of published articles through promotions

* Reduced timeline for article publication

Submit your articles and experience a new surge in publication services (https://www.peertechz.com/submission).

Peertechz journals wishes everlasting success in your every endeavours.

Copyright: (c) 2021 Taguri AE, et al. This is an open-access article distributed under the terms of the Creative Commons Attribution License, which permits unrestricted use, distribution, and reproduction in any medium, provided the original author and source are credited. 